\title{
A DESCONSTRUÇÃO DO SUJEITO NA RELAÇÃO ENTRE O PÓS-ESTRUTURALISMO E A ANALÍTICA QUEER
}

\author{
THE DECONSTRUCTION OF THE SUBJECT IN THE RELATION \\ BETWEEN POST-STRUCTURALISM AND ANALYTICAL QUEER
}

\author{
José Vitor Palhares dos Santos ${ }^{1}$ e Alexandre de Pádua Carrieri ${ }^{2}$
}

Recebido em: 13/06/2015

Aprovado em: 06/03/2016

\section{RESUMO}

Este ensaio teórico tem como objetivo analisar, a partir da epistemologia pós-estruturalista, de que modo a analítica queer problematiza e desconstrói algumas questões normalizadas do sujeito, como, por exemplo, as relações sociais de sexo e a emancipação. Trata-se de uma interpretação relevante para as Ciências Humanas e Sociais, pois a sociedade contemporânea ainda é permeada por inúmeros discursos segregacionistas, homogêneos e normalizadores, os quais visam à manutenção do status quo de certas categorias discursivas identitárias. Assim, por meio dessa análise, pode-se não só auxiliar o processo de emancipação de indivíduos subjugados e excluídos, como também romper com os ranços históricos presentes na nossa sociedade, os quais, muitas vezes, fortaleceram e fortalecem a ideologia acerca do sexo com base no conceito binário de gênero. Perspectivas como a analítica queer provocam e perturbam as formas convencionais de pensar e de agir e, por essa razão, podem ser ferramentas para a construção de um saber libertador.

Palavras-chave: Pós-estruturalismo; Analítica queer; Desconstrução.

\begin{abstract}
This theoretical essay aims to analyze, from the post-structuralist epistemology, how the analytical queer discusses and deconstructs some standard issues of the individuals, such as on social relations of sex and emancipation. It is a relevant interpretation of the humanities and social sciences because the contemporary society is still permeated by numerous segregationist, homogeneous and normalizing discourses, which aim at maintaining of the status quo of certain identity discursive categories. Thus, through this analysis, one can not only assist the process of emancipation of subjugated and excluded individuals, but also break with the historical biases present in our society, which often strengthened and still strengthen the ideology about the issue of sex oriented by binary concept of gender. Approaches like analytical queer provoke and disturb the conventional ways of thinking and acting, and, therefore, may be one of the tools for building a knowledge liberating.
\end{abstract}

Keywords: Post-structuralism; Analytical queer; Deconstruction.

\footnotetext{
${ }^{1}$ Mestrando em Administração pela Universidade Federal de Minas Gerais (UFMG), Brasil. E-mail: titopalhares@hotmail.com. 


\section{Introdução}

A partir do final do século XIX, inúmeras mudanças marcaram a cultura ocidental, a qual passou por transformações nas artes, na política e na economia, por exemplo, levando ao surgimento de um período denominado de pós-modernidade (PETERS, 2000). Entretanto, Souza (2012), embasado em Jameson (1991) e Harvey (1992), pontua que, por ser complexa a elaboração de uma definição do termo pós-modernidade no campo da sociologia, os estudos organizacionais não apresentam um conceito único.

Diante disso, pode-se afirmar que a pós-modernidade envolve uma época histórica caracterizada por modificações em relação ao período moderno e está ligada diretamente à modernidade, devendo ser compreendida como uma ontologia (SOUZA, 2012), um período de tempo, um ethos,que abarca inúmeras epistemologias, tais como o feminismo, o marxismo, o estruturalismo e o pós-estruturalismo (PETERS, 2000). E, apesar de o termo pós-modernidade gerar algumas divergências no campo dos estudos organizacionais naquilo que concerne à sua definição, é importante destacar que, no contexto deste ensaio teórico, falar-se-á sobre essa questão, mas não com profundidade, uma vez que o foco consiste na interpretação da analítica queer a partir do pós-estruturalismo, o qualé uma corrente epistemológica que emergiu na pós-modernidade.

A analítica queer surge dentro do contexto pós-estruturalista e pode ser compreendida, sob a perspectiva de Souza e Carrieri (2009), como uma analítica que observa a fragmentação a partir de uma visão alternativa para maior interação na edificação das práticas organizacionais, interpretando e levando em consideração as relações de poder (FOUCAULT, 1996) que estabelecem nos ambientes de trabalho práticas não somente opressivas, mas principalmente produtivas, direcionadasà sexualida- de e ao gênero. Além disso, o pós-estruturalismo não deve ser visto como um corpo unitário e coerente de pensamento, mascomo um campo heterogêneo de pensamentos que apresentam similaridades e diferenças (NEWMAN, 2007). Sendo assim, é importante ressaltar que este artigo é fundamentado em autores pós-estruturalistas franceses, como Foucault (1984) e Derrida (1995), os quais influenciaram a elaboração da analítica queer, descrita, principalmente, a partir de estudos elaborados por Butler (1990, 2003) e Sedgwick (2007).

Desse modo, o objetivo deste ensaio teórico é analisar, a partir da epistemologia pós-estruturalista, de que forma a analítica queer problematiza e desconstrói algumas percepções normalizadas relacionadas ao sujeito, como, por exemplo, as relações sociais de sexo e a emancipação. Ademais, procura-se entender a incoerência da expressão "teoriaqueer" dentro do contexto pós-estruturalista, uma vez que, se parte do princípio de que, sendo ela pós-estruturalista, deve ser concebida como uma analítica e não como uma teoria: ela tem como ponto de partida os processos discursivos de categorização e identificação do sujeito, interrogando a forma como as fronteiras da diferença são construídas, conservadas ou dispersadas (MISKOLCI, 2009).

Assim, o presente estudo mostrase relevante, pois, além de debater aspectos pouco discutidos nos estudos organizacionais brasileiros relacionados à produção de identidades e subjetividades, contribui para revelar a produção da diferença, a invisibilidade e ainferiorização de algumas identidades relacionadas à sexualidade e ao gênero, aspectos que, muitas vezes, demonstram seu reflexo a partir da interiorização do estigma (SARAIVA; IRIGARAY, 2009). Além disso, trata-se de uma interpretação relevante dentro dos estudos organizacionais, que também explora interfaces distintas do mainstream da Administração, uma vez que a socie- 
dade contemporânea ainda é permeada por inúmeros discursos segregacionistas, homogêneos e normalizadores que visam à manutenção do status quo de certas categorias discursivas identitárias dentro das organizações.

Desse modo, além desta introdução, este artigo está estruturado em quatro seções. A seção seguinte descreve as percepções sobre a temática do pós-estruturalismo e as suas principais características, seguida pela apresentação, no terceiro tópico, da analítica queer. A quarta seção refere-se à interpretação da relação entre a analítica queere o pós-estruturalismo e à importância dessa analítica para a compreensão da problematização dos sujeitos. Por fim, na última seção, são apresentadas as considerações finais deste ensaio.

\section{0 pós-estruturalismo e suas percepções}

O pós-estruturalismo pode ser compreendido como uma gama de estratégias teóricas que interagem com o que é denominado de condição pós-moderna. Contudo, a pós-modernidade não deve ser entendida apenas como uma etapa histórica atual ou um período de tempo em que se faz política, arte e filosofia (NEWMAN, 2007). De acordo com Eagleton (1998), a pós-modernidade é uma perspectiva que questiona noções clássicas de verdade, objetividade, razão, identidade, metanarrativas de legitimação, dentre outros elementos tidos como definitivos de explicação. Dessa forma, a pós-modernidade deve ser percebida como determinada perspectiva crítica sobre a própria modernidade (NEWMAN, 2007) ou como uma modernidade nova e aprimorada, purificada de suas pretensões utópicas altamente modernistas (SCOTT, 1998).

Visto isso, pode-se, então considerar o prefixo "pós" como um marcador histórico ou teórico (EAGLETON, 1998)? Segundo Rouleau e Clegg (1992), devemos tomar a pós-modernidade tanto como uma forma de conhe- cimento quanto como uma realidade histórica. Lyotard (1988) compreende a pós-modernidade como um período cronológico posterior à era moderna, caracterizada pela fragmentação dos sujeitos, dos discursos, dos fenômenos e da realidade - trata-se, portanto, não apenas de um período cronológico histórico, mas também de um momento de questionamento, reflexão e problematização da modernidade. Desse modo, assume-se neste trabalho uma dupla compreensão do conceito de pós-modernidade, que abrange a noção de conhecimento e, ao mesmo tempo, de um período cronológico histórico.

Para Souza (2012), as diferenças entre as definições de pós-modernidade e de pós-estruturalismo ainda não estão bem delineadas em trabalhos organizacionais sobre o tema, o que impulsiona ainda mais possíveis interpretações equivocadas. Por isso, antes de atribuir uma definição ao pós-estruturalismo, faz-se necessário definir as bases que o constituem.

O pós-estruturalismo possui como objeto de estudo o estruturalismo. Porém, apesar dessa proximidade entre os nomes, o pós-estruturalismo ainda é confundido com o pós-modernismo, e, apesar de haver algumas questões filosóficas e históricas comuns entre esses dois movimentos, ambos possuem objetos teóricos completamente distintos: um atém-se ao estruturalismo, e o outro, ao modernismo (PETERS, 2000).

$\mathrm{O}$ estruturalismo, objeto de críticas do pós-estruturalismo, sofreu grande influência da Linguística, principalmente por parte de Jakobson (2003) e Saussure (2006), e tem como base a ideia de que existe uma estrutura que é própria do indivíduo, não levando em consideração a ação dos sujeitos diante dessas estruturas(PETERS, 2000). Ou seja, a principal finalidade de uma interpretação estruturalista é entender o que existe de universal no homem, que possa ser observado e apreendido pelo saber científico. Assim, uma contribuição relevante do estruturalismo para as 
ciências sociais e humanas é que a formalização, na epistemologia estruturalista, é interpretação (ARAÚJO, 1993).

Desse modo, Foucault (2000) coloca que o estruturalismo é fortemente influenciado pelo formalismo europeu. Trata-se de uma contraposição às concepções humanistas, uma vez que busca romper com a concepção de sujeito apresentada pelas correntes do Humanismo e do Existencialismo. Logo, por um lado, se essas duas correntes tendem a inserir o sujeito no cerne de sua interpretação e de seu referencial teórico, por outro, o estruturalismo enxerga esses mesmos sujeitos como formados e determinados pela estrutura (PETERS, 2000).

Por isso, como uma epistemologia, Calás e Smircich (1999) afirmam que, por o pós-estruturalismo ser compreendido como uma representação no campo do saber que surgiu no período pós-moderno, esse movimento deve ser descrito em consonância com o estruturalismo, que surgiu aproximadamente no mesmo período e precede o pós-estruturalismo. Dessa forma, ao abordar o pós-estruturalismo como uma corrente epistemológica, é possível descrevê-lo como um movimento que se originou a fim de responder questões filosóficas sobre o status científico do estruturalismo (que tinha como intenção se tornar um megaparadigma nas ciências sociais) (PETERS, 2000).

Dessa maneira, o pós-estruturalismo, apesar de levar em consideração a estrutura, busca compreender os sujeitos como seres fragmentados, com base, por exemplo, nos seus discursos, os quais são vistos não apenas por meio da fala e escrita, mas também por meio das vestes, da música, da arquitetura, da culinária e das práticas esportivas, isto é, dos variados sistemas de saber e poder (RAJAGOPALAN, 2006). O estruturalismo defende que a linguagem é o centro da vida sociocultural do homem, sendo considerada como um sistema semiótico e de autorreflexo (PETERS, 2000). Nesse contexto, Newman (2007) afirma que o pós-estruturalismo não refuta a ideia de que a subjetividade é construída de modo discursivo por situações exteriores à linguagem, mas não defende que haja uma estrutura padrão e essencialista, questionando conceitos como unicidade, consistência e estabilidade, presentes na concepção estruturalista.

Então, ainda de acordo com $\mathrm{Ne}$ wman (2007), esse processo da desconstrução do modelo estruturalista pode ser feito de duas maneiras: concebendo a existência de discursos hegemônicos, que visam à manutenção das relações de poder; e analisando a estrutura como algo indeterminado, instável e incompleto. Ao fazer referência a Derrida (1995), Newman (2007) aponta que a estrutura em si não possui essa unicidade e deve ser compreendida como algo fragmentado e incompleto; por isso, ao discorrer sobre pós-estruturalismo, deve-se pensar que este não concebe em seu âmago a ideia do essencialismo nem a ideia de um modelo moral e racional preestabelecido e universal.

Calás e Smircich (1999) apontam que, dentro do pós-estruturalismo, é nítida a ocorrência de um processo de descentralização do sujeito que, ao contrário de ser algo originário, possui em sua subjetividade um movimento de duplo sentido caracterizado pela produção e pelo efeito, o qual está presente em uma conexão complexa de narrativas e práticas que sofrem alterações. Logo, Souza, Souza e Silva (2013) descrevem que, em uma concepção pós-estruturalista, a subjetividade é plural, apoiando-se na expressão polifônica e não conhecendo nenhuma instância de condicionamento que leve a outras instâncias de condicionamento, segundo uma causalidade unívoca. Nesse contexto, Guattari (1992) coloca que não se pode conceber o coletivo de forma segregada do indivíduo, pois o coletivo não consiste em coisas dadas, mas se forma por meio de processos que se cruzam, construindo diferentes sentidos.

O pós-estruturalismo traz consi- 
go outra questão que é o processo de problematização do sujeito. Nesse contexto, conforme descrevem Souza et al. (2013), não se pretende, no pós-estruturalismo, estudar as questões relacionadas com a estrutura, mas aquilo que concerne ao processo de problematização do sujeito. Não se analisam mais os comportamentos, a sociedade e suas ideologias, mas as problematizações por intermédio das quais o sujeito se mostra enquanto um ser pensado e as diferentes práticas por meio das quais as problematizações acontecem, influenciando o processo de constituição do ser (SOUZA; SOUZA; SILVA, 2013).

Diante disso, outro ponto fundamental na epistemologia pós-estruturalista é a rejeição ao binarismo e a concepção da sexualidade a partir das relações sociais de sexo, assunto esse que será detalhado nos tópicos seguintes, ao discorrer sobre a relação do pós -estruturalismo com a analítica queer. Resumidamente, pode-se afirmar que o objetivo do pós-estruturalismo ao rejeitar o binarismo é pensar além da relação homem/mulher, demonstrando que essa relação não é apenas natural, mas baseada também em oposições situadas dentro de um contexto histórico já construído. Assim, o sujeito não nega o diferente, mas aprende a negá-lo, sendo a aceitação da diferença o viés pelo qual o indivíduo irá alcançar o seu processo de desconstrução e construção, atingindo a emancipação (DERRIDA, 1995).

Ao se falar em emancipação dentro do contexto pós-estruturalista, devese pontuar que essa epistemologia não leva em consideração grandes acontecimentos ou movimentos, como as metanarrativas libertadoras ou as soluções universalizantes em sua essência, mas busca desconstruí-las e reinterpretá-las a partir do processo de ressignificação, já que a universalização tende a anular o processo de subjetivação à medida que não conduz o indivíduo para a emancipação (GUATTARI, 1992). Por isso, é de grande relevância, dentro dos estu- dos pós-estruturalistas, que o discurso hegemônico seja desconstruído, já que, conforme Laclau (2000), só haverá processo de hegemonia se a relação entre o universal e o particular for suprimida - o universal será sempre caracterizado por um conteúdo vazio e representado por algo oriundo do particular, de modo que, para que o particular se torne homogêneo, é necessário que seja capaz de unir em si todas as demais particularidades em torno de um interesse comum.

Além disso, segundo Souza et al. (2013), o projeto emancipatório proposto por alguns autores do pós-estruturalismo, como Guattari (1992), Rolnik (1997) e Foucault (2002), não pode ser entendido como o alcance da liberdade do homem em relação às ideologias prejudiciais presentes em seu contexto social, pois, caso isso ocorresse, nos levaria a crer que, em algum período da história, o homem não sofria influência das relações de poder e que os diferentes processos que o circundam acabaram o alienando. Ressalta-se, ainda, que o processo de alienação não significa produção de uma falsa consciência, mas sim uma perda significativa em relação ao direcionamento que nos levaria ao bem - estar da coletividade e ao alcance dos resultados advindos da emancipação.

Nesse contexto, Mendonça (2008) aponta que o processo da universalização é algo que deve ser visto como incompleto e sem acabamento. Só poderá haver a constituição do processo de hegemonia se houver a presença de um significante vazio, que busque unificar os indivíduos de uma sociedade; por outro lado, a sociedade poderia se tornar mais justa se o destino do processo de emancipação estivesse ligado ao rompimento com a constituição de discursos universais e hegemônicos e prejudiciais.

Portanto, pode-se afirmar que a "emancipação é algo múltiplo, heterogêneo, processual, contingencial, sempre envolto por poder e em constante movimento" (SOUZA et al., 2013, p. 211). Por isso, os autores definem que, 
no contexto pós-estruturalista, não existe uma divisão ou separação entre aquilo que é universal e particular, já que a existência do universal depende do particular e a emancipação consiste em um processo e não em um fim em si mesmo. O pós-estruturalismo não acredita, assim, em movimentos e metanarrativas libertadoras nem em ideias universalizantes para o processo de constituição do sujeito.

No que tange ao contexto empresarial, o pós-estruturalismo refuta a ideia de modelos e soluções universais para as organizações, concedendo visibilidade às práticas organizacionais locais (SOUZA; CARRIERI, 2010). Além disso, desnaturaliza a noção de metanarrativas organizacionais e de organização enquanto uma estrutura rígida, homogênea e não problemática. Ao contrário, no pós-estruturalismo, há uma visão reflexiva e processual das organizações, em que estas passam a ser entendidas não mais como substantivos (ou seja, como algo fixo e estável) (CHIA, 1995; TSOUKAS, CHIA, 2002), mas como verbos (isto é, como processos de práticas de organizar, que são difusas, complexas e instáveis) (DUARTE; ALCADIPANI, 2016).

Além disso, vale ressaltar que as identidades no contexto pós-estruturalista são concebidas como não essencialistas, ou seja, são múltiplas, cambiantes e fluidas (CARRIERI et al., 2008). Dessa forma, há a rejeição da polarização de binarismos como homem/ mulher e heterossexual/homossexual (PARKER, 2001), cabendo aos gestores organizacionais compreenderem e disseminarem essas ideias para os demais trabalhadores da empresa, para que haja mais diversidade e aceitação das diferenças, forma pela qual os sujeitos poderão alcançar seu processo de (des) construção, atingindo, assim, sua emancipação (DERRIDA, 1995).

\section{A analítica queer e o processo da normalização}

De acordo com Miskolci (2009), a analítica queer surge nos Estados Unidos em fins da década de 1980, tendo como base um processo de oposição aos diferentes estudos da Sociologia sobre as minorias sexuais e as relações sociais de sexo. Dessa maneira, o autor enfatiza que o diálogo entre essa analítica e a Sociologia ganhou destaque devido a inúmeros estranhamentos e a certa afinidade em relação ao entendimento sobre o fazer sexual visto como uma construção histórica e social.

Nesse período, os primeiros estudiosos dessa analítica recusam uma ideia minorizante de alguns socioantropólogos, conduzindo-se em direção a uma concepção que duvidasse dos pressupostos teóricos normalizadores que caracterizavam a Sociologia canônica (SEIDMAN, 1996). Por essa razão, pode-se afirmar que a função da palavra queer, nesse contexto, não se veste de uma roupagem que tem como objetivo menosprezar os movimentos identitários, mas apontar, de forma contundente e sistematizada, as diferentes armadilhas do hegemônico em que estão alocados, contestando os regimes normalizadores (GAMSON, 1996).

Ao analisarmos os pressupostos de Jacques Derrida em relação ao conceito de suplementaridade e ao seu ponto de vista sobre o processo da desconstrução, observa-se que, na analítica queer, essa suplementaridade vem com o objetivo de revelar que os significados são ordenados por meios diferentes em uma relação de pertencimento e não pertencimento, isto é, o que está fora está dentro, e o que parece comum é histórico (DERRIDA, 2004).

Além disso, pode-se afirmar que a analítica queer coloca como ponto fundamental desse campo de estudo a necessidade de estabelecer uma análise sobre as contraposições binárias, como a de homo/heterossexualidade, para re- 
contextualizá-las e retificá-las pelos atos de significação, uma vez que o indivíduo se encontra imerso em uma relação lógica do binarismo, na qual toda tentativa de rompimento acaba o conduzindo e o reinscrevendo nesse mesmo contexto.

Por essa razão, a analítica queer compreende que tudo está diretamente relacionado com dispositivos históricos de poder, uma vez que esses dispositivos, conforme Foucault (1996), podem ser considerados um agrupamento de discursos e práticas sociais distintas que estão presentes dentro de uma rede, estabelecendo-se e fortalecendo-se a partir de diversos elementos, como o moralismo, os pressupostos científicos e até mesmo a própria literatura. Então, nesse contexto, vale pontuar que certos modos atuais de dominação do indivíduo homossexual estarão diretamente imbricados com a insatisfação de outros homens em relação aos laços eróticos entre homens, sendo esse sentimento de insatisfação projetado na imagem estereotipada e estigmatizada do homossexual (SEDGWICK, 2007).

De acordo com Sedgwick (2007), os dinamismos dos modelos sociais contemporâneos não se separam dos modelos sexuais, isto é, existe uma estrutura que se caracteriza dentro de uma dualidade heterossexual/homossexual com o objetivo de valorizar um e menosprezar o outro. Dessa forma, valoriza-se a heterossexualidade, naturalizando-a, e coloca-se a homossexualidade em um patamar de subjugação, caracterizando-a como algo não natural. Assim, para Miskolci (2009, p. 157), a analítica queer propõe que estudar a sexualidade "implica explorar os meandros da heteronormatividade, tanto a homofobia materializada em mecanismos de interdição e controle das relações amorosas e sexuais entre pessoas do mesmo sexo, quanto a padronização heteronormativa dos homo orientados".

Diante disso, pode-se afirmar que a analítica queer consiste em um movimento subversivo, que arrisca o impensável, desestabilizando as certe- zas presentes nas práticas sociais dos indivíduos. Queer "é um jeito de pensar e de ser que não aspira o centro nem o quer como referência; um jeito de pensar e de ser que desafia as normas regulatórias da sociedade, que assume o desconforto da ambigüidade, do indecidível" (LOURO, 2004, p. 7-8).

Além disso, a analítica queer lida com sujeitos sem muitas alternativas e destituídos de um espaço no presente. Sua força motriz está ligada à relação entre raça e sexualidade, uma vez que é dentro dessa relação que se cria o processo de normalização, o qual faz com que alguns indivíduos sejam vistos como menos humanos ou abjetos (MISKOLCI, 2009). Desse modo, Miskolci(2009), em seu estudo sobre a analítica queer, descreve que existe no sistema moderno uma ideia que encara a sexualidade como um conjunto de saberes e práticas que determina toda a vida em sociedade e que, por essa razão, faz-se necessário o foco na desconstrução de processos que tendem a classificar, hierarquizar e normatizar essas relações, uma vez que, ao romper com esses conceitos preestabelecidos, principalmente no que tange à sexualidade, o indivíduo está rompendo com fatores normalizadores, como, por exemplo, o binarismo. Ou seja, a emancipação das práticas de dominação da contemporaneidade está presente em uma visão pós-identitária e não binária das coisas, perspectiva essa que atua como uma possibilidade para a construção de uma nova realidade social dentro de diferentes contextos, como o das organizações (SOUZA e CARRIERI, 2010).

Souza e Carrieri (2010) pontuam que a analítica queer reflete sobre a presença de uma visão pós-identitária que entende o processo de fragmentação do sujeito como uma alternativa para um engajamento do indivíduo em seu contexto social, reduzindo ou eliminando a repressão sofrida por ele a partir de práticas opressivas que se direcionam à sexualidade. Logo, como evidenciado 
por Foucault (1988), a caracterização dos indivíduos a partir de uma diferenciação biológica não é algo comum e natural, mas um dispositivo de poder que visa manter as relações em sociedade a partir de um processo binário de normalização do sexo.

De acordo com Costa (1995), esse processo bipolar do sexo é que diferencia o homem da mulher e tenta estabelecer diferenças de comportamento entre ambos, atendendo aos interesses das classes dominantes: capitalistas, nacionalistas e individualistas heterossexuais e brancos. Foucault (1988) entende que habitualmente o sexo é percebido como reduzido a um sistema daquilo que pode ou não ser praticado, marginalizando os indivíduos que não se enquadram nesse padrão, isto é, o padrão heteronormativo. Por esse motivo, pode-se considerar a analítica queer como uma importante ferramenta para realizar a desconstrução desses processos de normalização, uma vez que ela aponta para um entendimento de que quase todos os acontecimentos recentemente compreendidos como discrepantes de padrões sociais preestabelecidos não devem ser encarados como erro ou desvio, mas como diferenças resultantes de processos contínuos de inferiorização (MISKOLCI, 2009).

Assim, dentro dessa lógica binária, sempre haverá um lado que será desvalorizado e inferiorizado, sendo classificado como minoria, mas que pode ser supostamente aceito pela sociedade, pois a definição de relações sociais de sexo proposta pelo binarismo reforça essa ideia do masculino e feminino e sua concepção do desejo, a partir do determinismo biológico do sexo (LOURO, 2004). A analítica queer vai de encontro a essa ideia e permite explorar de forma crítica e mais adequada as relações entre o indivíduo e a sociedade e a linguagem e a consciência, descentrando o sujeito de modo a complementar os determinantes sociais com a subjetividade, visando analisar e reconstruir os processos sociais (MISKOLCI, 2009).
Portanto, de acordo com Miskolci (2009), o foco da analítica queer não é a defesa dos estigmatizados, mas a crítica e o rompimento com o binarismo de relações sociais de sexo que cria o processo da estigmatização. $\mathrm{O}$ autor busca romper com lógicas preestabelecidas a partir de um processo de hierarquia e subalternização, as quais estão inseridas em diferentes contextos e que propiciam e legitimam, muitas vezes, ações de violência e intolerância, até mesmo nas organizações. Por esse motivo é que a analítica queer tem sido estudada e utilizada no meio acadêmico, pois ela mostra que as identidades estão inseridas em vivências culturais imersas em relações sociais, regidas por discursos de poder, e que é na questão da sexualidade que se encontram essas diferentes relações dominantes e os discursos hegemônicos, os quais visam à manutenção da ordem (FOUCAULT, 2004).

No que se refere ao ambiente organizacional, vale ressaltar que a gestão é configurada na matriz heterossexual (PARKER, 2001). Dessa forma, a heterossexualidade é tida como algo natural dentro das empresas, enquanto que a homossexualidade é subjugada. É nesse contexto, devido ao heterossexismo e à homofobia, que muitas pessoas são marginalizadas e discriminadas nas organizações, sendo obrigadas, em muitos casos, a não revelarem sua orientação sexual para os colegas de trabalho para não serem prejudicadas em suas carreiras profissionais. Dentre as principais possíveis dificuldades enfrentadas por quem não se encaixa na matriz heterossexual dentro das organizações, é possível citar: a discriminação no processo seletivo da empresa, em que muitas vezes os homossexuais não são contratados devido à sua orientação sexual; a perda de emprego ou até mesmo de uma possível promoção quando se descobre o sujeito homossexual; a homossexualidade como tema constante de piadas e desprezo pelos colegas de 
trabalho; e avaliações de desempenho baseadas primordialmente na identidade dessas pessoas, e não no trabalho desenvolvido na empresa (SIQUEIRA; ZAULI-FELLOWS, 2006).

Desse modo, a compreensão a respeito da analítica queer pelos gestores organizacionais pode trazer diversos benefícios para as empresas e para seus funcionários, como a melhoria nas relações de trabalho mediante a suspensão de práticas opressivas e discriminatórias, contestando e desconstruindo os regimes normalizadores e rompendo com os processos que tendem a classificar, hierarquizar e normatizar as relações ali estabelecidas.

\section{A analítica queer e sua relação com o pós-estruturalismo}

Segundo Souza (2012), por abarcar um conjunto de perspectivas pósmodernas, o pós-estruturalismo engloba, em sua maioria, perspectivas que visam desconstruir relações hegemônicas de poder que se pautam em discursos históricos preestabelecidos, os quais buscam manter no poder aqueles que já se encontram nele. Por isso é que se pode caracterizar a analítica queer como um conjunto de ideias propostas por diferentes autores que visam uma análise da normalização, interrogando a forma como as fronteiras das diferenças são construídas, mantidas e dissipadas (MISKOLCI, 2009).

Tal analítica está inserida no contexto pós-estruturalista e, desse modo, traz consigo as características dessa epistemologia, pois, como pontua Louro (2004), na pós-modernidade, parece vital pensar nos processos mais confusos, difusos e múltiplos que compõem as relações sociais como algo a ser desconstruído - nesse contexto, o sujeito é ele próprio dividido, fragmentado e cambiante. Então, nas palavras dessa autora, mesmo que os indivíduos regressem a seu ponto de partida, após a fragmentação, eles jamais serão os mesmos.
Para Butler (2003), a emancipação do sujeito subjugado pelo discurso binário de relações sociais de sexo, conforme citado na seção anterior, ocorre a partir de um processo de desconstrução da ideia dos corpos feminino e masculino, aos quais são atribuídos significados culturais. Porém, a analítica queer, como uma ideia pós-estruturalista, mostra que, apesar disso, a sequência é subvertida e que, a partir do instante em que isso ocorre, entram em cena as relações de biopoder, as quais visam manter o domínio e a ordem daqueles que se subverteram conforme o padrão normalizador determinado pela biologia do sexo (FOUCAULT, 1988).

Segundo Bauman (2001), o cenário social, a fragmentação e a incerteza não podem ser vistos como algo casual e momentâneo, pois esses são os principais traços da pós-modernidade, que são encontrados na epistemologia pós-estruturalista, dentro da qual está a analítica queer. As relações sociais de sexo, nesse contexto, chegam como uma forma de denotar construções culturais e papéis sociais relacionados à imagem do homem e da mulher. Todavia, essa imagem não pode nem deve ser concebida como padrão, já que, para o pós-estruturalismo, esse termo é inadequado. Nessa situação, a analítica queer entende que o processo é incompleto e demanda reformulação: trata-se de efeitos oriundos das instituições de poder, dos discursos existentes e das práticas históricas que são identificadas no convívio social (LOURO, 2004). Em outras palavras, a autora aponta que

uma matriz heterossexual delimita padrões a serem seguidos e, ao mesmo tempo, paradoxalmente, fornece pauta para as transgressões. É em referência a ela que se fazem não apenas os corpos que se conformam com as regras de relações sociais de sexo e sexuais, mas também os corpos que se subvertem (LOURO, 2004, p. 17). 
Nos últimos séculos, inúmeras correntes epistemológicas, como o determinismo e o positivismo, buscaram compreender o processo de formação da sexualidade a partir dessa concepção binária de relações sociais de sexo. Contudo, o que certamente não fica claro é que essas mesmas áreas do conhecimento apresentam discursos hegemônicos de poder, os quais estão imbricados em uma relação quase que simbiótica na formação discursiva de alguns indivíduos. A esse respeito, Louro (2004) descreve que se proliferam, cada vez mais, os discursos acerca do sexo e que as diferentes sociedades permanecem inseridas em um processo de reprodução contínua desses mesmos discursos, sendo um sobre o próprio prazer e o outro sobre o prazer do saber.

Dentro da analítica queer e no contexto pós-estruturalista, o maior de todos os desafios é compreender que as posições de relações sociais de sexo são diferentes e múltiplas e que é impossível lidar com elas dentro de um esquema que polariza as coisas em masculino/feminino, ou seja, admitir que essa fronteira vem sendo atravessada e que existem indivíduos que vivem exatamente nela (LOURO, 2004). Por esse motivo, a autora coloca, a partir dessa analítica contra a normalização do sexo, que a homossexualidade e o sujeito homossexual, por exemplo, foram termos criados no século XIX. Se antes as relações sexuais eram concebidas como algo pervertido, proibido, pecaminoso e indesejável, a partir de meados daquele século, a prática sexual passa a ser descrita de forma segregacionista, marcando, reconhecendo e classificando os indivíduos a partir dos termos heterossexual e homossexual, sendo este visto como um desvio da norma.

A analítica queer propõe que, nessas circunstâncias, assim como aborda Foucault (1984, 1985, 1988), divisões como masculino e feminino, macho e fêmea, heterossexual e homossexual são produtos de relações de poder, já que a sexualidade só pode ser estudada sob um ponto de vista histórico ou, como o próprio Foucault (1984) pontua, a partir de uma genealogia. Nesse caso, observa-se que, como mencionado, a sexualidade constitui-se em uma dinâmica sobre a própria sexualidade, motivo pelo qual o binarismo do sexo em relação à natureza deve ser eliminado em prol de uma análise crítica sobre questões como relações sociais de sexo a partir de concepções históricas, discursivas e de significação, que irá desconstruir supostas verdades impostas sobre algumas minorias (FOUCAULT, 1996).

Por essa e por algumas outras razões é que a analítica queer é considerada um conjunto de ideias pós-estruturalistas, já que ela critica esse modelo binário do sexo, rejeita a classificação dos indivíduos em identidade sexuais, combate a heteronormatividade e desnaturaliza as questões relacionadas ao sexo (SOUZA; CARRIERI, 2010). Dessa forma, como afirma Louro (2008), para o pensamento queer, o polo masculino está presente no feminino e vice-versa, o que implica compreender que cada um deles é fragmentado e dividido, sendo necessária, então, a desconstrução do binarismo das relações sociais de sexo.

Assim, o termo queer, que se originou, apriori, como um insulto à comunidade gay, passa a ser incorporado pelo pós-estruturalismo, que coloca a analítica queer como um reflexo de uma nova configuração social fragmentada, que representa o diferente, o que é subjugado, assinalado e tolerado. Por isso, a sua forma de ação é vista como algo transgressivo e perturbador (LOURO, 2004).

Além disso, as perspectivas queer não devem ser consideradas como uma teoria, mas como uma analítica - motivando a utilização desse termo no presente estudo -, visto que ela engloba um processo de análise do homossexual, mostrando que as identidades sociais são efeitos de um processo construído e organizado a partir de relações de poder das classes dominantes (MISKOLCI, 
2009). Nesse contexto, Louro (2004) evidencia que diversas foram as condições que propiciaram o surgimento do movimento queer; por isso, ele precisa ser compreendido como parte de um quadro mais amplo do pós-estruturalismo - uma vez que a analítica queer está vinculada ao pensamento ocidental do século XX - o qual problematiza algumas noções do sujeito, como as de identidade e de agência.

Para Derrida (2004), todas as lógicas precisam ser abaladas a partir de uma ação que busca desconstruir, reverter, desestabilizar e desordenar os pares propostos pelo binarismo das relações sociais de sexo. Logo, desconstruir esses discursos implica, necessariamente, provocar, instigar, perturbar e subverter uma ordem preestabelecida que se pauta em discursos afirmativos. Portanto, ao estabelecer que o objetivo de uma ação precisa ser o questionamento e a análise, deve-se indicar um método a ser seguido; neste caso, o mais adequado, de acordo com Louro (2004), é o procedimento da desconstrução.

No âmbito da sexualidade, a desconstrução da oposição binária revelaria a interdependência e a fragmentação dos polos preestabelecidos, de modo que, para os teóricos da analítica queer, a oposição heterossexualidade/homossexualidade, no contexto pós-estruturalista, deve ser abalada e criticada por meio dos procedimentos da desconstrução (LOURO, 2004). De acordo com teóricos dessa corrente de pensamento,ao romper com essa lógica binária, devem-se desconstruir também os efeitos que dela surgem, tais como a classificação, a dominação e a exclusão, pensando nas ambiguidades, na pluralidade e na fluidez das identidades sexuais de relações sociais de sexo, que trarão à tona novas formas de pensamento, cultura, conhecimento, poder e educação. Como aponta Swain (2001), ao balançar as supostas verdades que definem e limitam o indivíduo, revelase um caminho que fará surgir uma rea- lidade múltipla.

Por esse motivo, quando Carrieri (2012) discorre sobre o potencial da crítica pós-estruturalista em relação a sua possibilidade de contraposição e contestação de discursos, reitera-se o fato de que a desconstrução é benéfica no sentido de ampliar e melhorar as relações em sociedade, já que traz consigo uma nova realidade. Pelo fato de ainda existir o desprezo ao sujeito homossexual nas organizações e na nossa sociedade em geral, é fundamental compreender não apenas como se constituíram as posições de sujeito no ambiente social, mas colocar em xeque o posicionamento binário que subjaz 0 regime, inscrevendo-se na produção do saber, na organização social, nas práticas cotidianas e no exercício do poder (LOURO, 2004).

Assim, de acordo com Louro (2004), a analítica queer revela que a homossexualidade é fruto de um regime de poder/saber, ou seja, ela é mais do que uma identidade social minoritária, uma vez que, por suas condições de emergência e constituição, configura-se, talvez, como uma política pós-identitária. Logo, na visão de Spargo (1999), o termo queer, utilizado para definir a analítica em questão, pode ser compreendido como algo que se contrapõe ao normal, pois, na lógica determinista, o sexo natural é visto como aquilo que é determinado pela natureza.

Desse modo, muitas das relações sociais que estão envoltas pela concepção binária de gênero acabam gerando estigmas e marginalizando as minorias que não se enquadram nesse padrão, pois, como evidenciado por Saraiva e Iragaray (2009), o estigma, por se fundar em uma relação de assimetria que atribui termos depreciativos a uma pessoa ou a um grupo, no caso, as minorias, é um fenômeno socialmente construído a partir de implicações negativas, que visam à exclusão e segregação. Por meio dessa compreensão de estigma, o qual é gerado a partir do processo de 
normalização e deve ser desconstruído pela analítica queer, o poder se instala, já que minorias são grupos que têm sua condição social sequestrada, em geral, por relações assimétricas constituídas e norteadas pela hegemonia masculina (BOURDIEU, 2007). Essa hegemonia masculina também é encontrada no ambiente organizacional via divisão do trabalho pautada no gênero, em que o trabalho da mulher é considerado leve e fácil e o trabalho do homem é considerado pesado, o que justificaria um maior salário aos homens mesmo se tratando de um mesmo cargo. Visto isso, conforme a perspectiva de Foucault (1996), faz-se necessária a desconstrução dos discursos hegemônicos e totalitários, observando o que subjaz esses discursos e tendo em vista o processo de emancipação do sujeito, o qual poderá levar à edificação de um mundo de singularidades que, em suma, constituirá uma convivência plural.

\section{Considerações finais}

Conforme discutido neste estudo, entende-se que o processo de formação do pós-estruturalismo como uma epistemologia do mundo pós-moderno e da analítica queer como algo que está alocado no pós-estruturalismo ainda é latente e de grande relevância para as ciências humanas e sociais, uma vez que essas perspectivas revelam preconceitos, silenciamentos e exclusões, a partir de formações discursivas hegemônicas, demonstrando, também, o interesse de algumas classes dominantes em se manter no poder. Portanto, por ser o sujeito no pós-estruturalismo autônomo e não determinado pela estrutura, correntes de pensamento como a analítica queer podem, nesse contexto, desestabilizar e romper com diversas ideologias que estabelecem relações de causa e efeito para justificar o processo de dominação (SOUZA et al., 2013). Isto é, ela pode ser vislumbrada como algo alcançável, pois torna o processo de reflexão e emancipação do ser necessário, já que, dentro do cenário global, a sociedade é formada por múltiplas realidades.

Assim, quando Peters (2000) se refere ao pós-estruturalismo (pautado no processo da problematização e questionamento do cientificismo das ciências humanas), fica evidente a importância da analítica queer para a edificação de uma realidade que priorize o diferente. A partir de sua análise, pode-se não só auxiliar o processo de emancipação de indivíduos subjugados e excluídos, como também romper com os ranços históricos presentes na nossa sociedade, os quais, muitas vezes, fortaleceram e fortalecem a ideologia acerca da questão do sexo pautado no conceito binário de gênero.

Desse modo, conforme evidenciado por Louro (2004), o surgimento do pós-estruturalismo e das perspectivas a ele associadas provocaram muitas modificações sociais no terreno da sexualidade, mas que ainda são insuficientes para evitar processos de dominação, que geram exclusão e violência. Conforme a autora, perspectivas como a analítica queer provocam e perturbam as formas convencionais de pensar e de conhecer e, por essa razão, podem ser ferramentas para a construção de um saber libertador.

Assim sendo, queer compreende uma analítica de colocar-se contra a normalização, transbordando a esfera da sexualidade, uma vez que poderia ser utilizada para problematizar não somente as identidades sexuais, como também outros grupos identitários de raça, classe ou nacionalidade, por exemplo, que ditam, restringem e enquadram formas de ser e de viver. Destarte, quando se evidencia como o outro sujeito é constituído, é possível questionar as relações do eu com o outro. Nesse contexto, as diferenças seriam indispensáveis para a existência do próprio indivíduo, integrando-o e passando a auxiliar em sua (re)construção. A analítica queer no contexto pós-estruturalista permite, então, pensar a multiplicidade e fluidez das identidades e suscitar novas formas 
de refletir sobre o conhecimento, o poder, as culturas e as organizações.

Por falar em organizações, como traduzir a analítica queer para as práticas empresariais? Operários, técnicos, gestores e Chief Executive Officers (CEO's) gays, lésbicas, bissexuais, transexuais e travestis compõem a diversidade contemporânea das organizações. Entretanto, por serem instituições disciplinares e normatizadoras, nelas tudo o que é diferente tende a ser insuportável por transbordar as fronteiras do que é conhecido e do que é tido como aceitável. Muitos atores organizacionais, independente dos níveis hierárquicos, mostram-se, quase sempre, perplexos, perturbados e desafiados perante questões que, até pouco tempo atrás, poderiam ser solucionadas por intermédio de respostas seguras e estáveis. Agora, as verdades absolutas e as certezas esvaem-se, e os modelos universais mostram-se inapropriados: não é mais possível ignorar as "novas" práticas, os "novos" sujeitos e suas contestações.

Desse modo, necessita-se produzir a capacidade de desestabilizar e problematizar o conhecido e o que é tido como aceitável em busca da emancipação dos indivíduos. Fronteiras e limitações binárias de gênero ou sexo deverão ser transcendidas em busca de novas possibilidades de conhecer e de organizar as relações de trabalho. Nesse sentido, compreender a analítica queer no contexto pós-estruturalista é fundamental aos estudos organizacionais, uma vez que esta serve de ferramenta para reduzir e até mesmo suprimir o preconceito e a discriminação que ocorrem com indivíduos marginalizados nas organizações devido ao gênero ou à orientação sexual, valorizando a diversidade no espaço organizacional e melhorando as relações de trabalho para todos.

Por fim, espera-se que este trabalho suscite e fomente outros debates sobre os benefícios que a compreensão acerca da analítica queer no pós-estruturalismo, por meio da problemati- zação, desconstrução e denúncia das relações de opressão, pode ocasionar em todas as esferas sociais. Além disso, após todas as considerações feitas em relação à analítica queer e sua relação com o pós-estruturalismo, sugere-se que, para futuras pesquisas, não só ela, mas outras correntes pós-modernas, como, por exemplo, o desconstrutivismo, sejam estudadas e utilizadas para confrontar e desestabilizar os processos de dominação, a partir da desconstrução de discursos preestabelecidos não só em contextos como o organizacional, familiar e escolar, mas também no meio acadêmico, dentro dos quais circula o poder.

\section{Referências}

1. ARAÚJO, I. L. Introdução à filosofia da ciência. Curitiba: Ed. da UFPR, 1993.

2. BAUMAN, Z. Modernidade líquida. Rio de Janeiro: Jorge Zahar, 2001.

3. BOURDIEU, P. A dominação masculina. 5.ed. Rio de Janeiro: Bertrand Brasil, 2007.

4. BUTLER, J. Gender trouble: feminism and the subversion of identity.New York and London: Routledge, 1990.

5.

Bodies that matter: on the discursive limits of sex. New York: Routledge, 2003.

6. CALÁS, M. B.; SMIRCICH, L. Past Postmodernism? Reflections and tentative directions. The Academy of Management Review, v. 24, n. 4, p. 649-671, 1999.

7. CARRIERI, A. P. A gestão ordinária. 2012. Tese (Tese para concurso de Prof. Titular) - Faculdade de Administração, Universidade Federal de Minas Gerais, Belo Horizonte, 2012.

8. CARRIERI, A. P.; PAULA, A. P. P.; DAVEL, E. Identidade nas organizações: múltipla? Fluida? Autônoma? Or- 
ganizações \& Sociedade, Salvador, v. 15, n. 45, p. 127-144, Abril/Junho 2008.

9. CHIA, R. From modern to postmodern organizational analysis.Organization Studies, v. 16, n. 4, p. 579-604, 1995.

10. COSTA, J. F. A face e o verso: estudos sobre o homoerotismo II. São Paulo: Escuta, 1995.

11. DERRIDA, J. A escritura e a diferença. São Paulo: Editora Perspectiva, 1995.

12. Gramatologia. São Paulo: Perspectiva, 2004.

13. DUARTE, M. F.; ALCADIPANI, R. Contribuições do Organizar (Organizing) para os Estudos Organizacionais. Organizações \& Sociedade, v. 23, n. 76, p. 57-72, 2016.

14. EAGLETON, T. As ilusões do pósmodernismo. Rio de Janeiro: Jorge Zahar Editor, 1998.

15. FOUCAULT, M. História da sexualidade II: o uso dos prazeres. Rio de Janeiro: Edições Graal, 1984.

16.

História da sexualidade

III: o cuidado de si. Rio de Janeiro: Edições Graal, 1985.

17. História da sexualidade I: a vontade de saber. Rio de Janeiro: Edições Graal, 1988.

18. . A ordem do discurso. São Paulo: Edições Loyola, 1996.

19. . Estruturalismo e Pós-estruturalismo. In: MICHEL, F. A arqueologia das ciências e história dos sistemas de pensamento. Rio de Janeiro: Forense Universitária, 2000.

20. $A$ arqueologia do saber.

Rio de Janeiro: Fontes Universitária, 2002.

21. A ética do cuidado de si como prática de liberdade. In: FOUCAULT, M. (Ed.), Ética, sexualidade, política(pp. 264-287). Rio de Janeiro:
Forense Universitária, 2004.

22. GAMSON, J. Must identity movements self-destruct: a queer dilemma. In: SEIDMAN, S. QueerTheory/Sociology. Malden: Blackwell, p.395-419, 1996.

23. GUATTARI, F. Caosmose: um novo paradigma estético. Rio de Janeiro: Editora 34, 1992.

24. HARVEY, D. A condição pós-moderna: uma pesquisa sobre as origens da mudança cultural. São Paulo: Loyola, 1992.

25. JAKOBSON, R.Linguística e comunicação. Trad. José Paulo Paes. São Paulo: Cultrix, 2003.

26. JAMESON, F. Postmodernism, or the cultural logic of late capitalism. London: New York, 1991.

27. LACLAU, E. Identity and hegemony. In: BUTLER, J.; LACLAU, E.; ZIZEK, S. (Orgs.), Contingency, hegemony, universality: contemporary dialogues on the left. London: Verso, p. 44-89, 2000.

28. LOURO, G. L. Um corpo estranho: ensaios sobre sexualidade e teoria queer. Belo Horizonte: Autêntica, 2004.

29. LYOTARD, J. O pós-moderno. Rio de Janeiro: José Olympio, 1988.

30. MENDONÇA, D. A impossibilidade da emancipação: notas a partir da teoria do discurso. In MENDONÇA, D; RODRIGUES, L. P. (Orgs.), Pós-estruturalismo e teoria do discurso: em torno de Ernesto Laclau. Porto Alegre: EDIPUCRS, p. 63-70, 2008.

31. MISKOLCI, R. A Teoria Queer e a Sociologia: o desafio de uma analítica da normalização. Sociologias, v. 11, n. 21, p. 150-182, 2009.

32. NEWMAN, S. Power and politics in poststructuralist thougth:new theories of the political. London: Routledge, 2007.

33. PARKER, M. Fucking management: 
queer, theory and reflexivity. Ephemera, v. 1, n. 1, p. 36-53, 2001.

34. PETERS, M. Pós-estruturalismo e filosofia da diferença. Belo Horizonte: Autêntica, 2000.

35. RAJAGOPALAN, K. Review of "Talk and Social Theory" by Frederick Erickson. JournalofSociolinguistics, Londres, Reino Unido, v. 10, n.3, p. 412-416, 2006.

36. ROLNIK, S. Toxicômanos de identidade: subjetividade em tempo de globalização. In: LINS, D. S. (Org.), Cultura e subjetividade: saberes nômades. Campinas: Papirus, 1997, p. 19-24.

37. ROUleaU, L.; CleGG, S. R. Postmodernism and postmodernity in organizations analysis. JournalofOrganizationalChange Management, $v$. 5, n. 1, p. 8-25, 1992.

38. SARAIVA, L. A. S.; IRIGARAY, H. A. D. R. Políticas de diversidade nas organizações: uma questão de discurso?. Revista de Administração de Empresas, v. 49, n. 3, p. 337-348, 2009.

39. SAUSSURE, F. Curso de linguística geral. 27. ed. São Paulo: Cultrix, 2006.

40. SCOTT, J. C. Seeing like a state. New Haven: Yale University Press, 1998.

41. SEDGWICK, E. K. A Epistemologia do Armário. In: CadernosPagu. Tradução de Plinio Dentzien. Campinas: Núcleo de Estudos de GêneroPagu, 2007.

42. SEIDMAN, S. QueerTheory/Sociology. Malden: Blackwell, 1996.

43. SIQUEIRA, M. V. S.; ZAULI-FELLOWS, A. Diversidade e identidade gay nas organizações. GESTÃo.Org - Revista Eletrônica de Gestão Organizacional, v. 4, n. 3, p. 69-81, 2006.

44. SOUZA, E. M. Pós-modernidade nos estudos organizacionais: equívocos, antagonismos e dilemas. Cadernos EBAPE.BR, v. 10, n. 2, p. 270-283, 2012.
45. SOUZA, E. M.; CARRIERI, A. P. A analítica Queer e seu rompimento com a concepção binária de gênero. Revista de Administração Mackenzie, v. 11, $\mathrm{n}$. 3, art. 2, p. 46-70, 2010.

46. SOUZA, E. M.; SOUZA, S. P.; SILVA, A. R. L. O pós-estruturalismo e os estudos críticos de gestão: da busca pela emancipação à constituição do sujeito. Revista de Administração Contemporânea, v. 17, n. 2, p. 198-217, 2013.

47. SPARGO, T. Foucault and Queer Theory. Nova York: Totem Books, 1999.

48. SWAIN, T. N. Para além do binário: os queerse o heterogêneo. Gênero, Niterói, v. 2, n. 1, p. 87-98, 2. sem. 2001.

49. TSOUKAS, H.; CHIA, R. On organizational becoming: rethinking organizational change. Organization Science, v. 13, n. 5, p. 567-582, 2002. 